\title{
Enthusiasm for UK wave power survives high costs
}

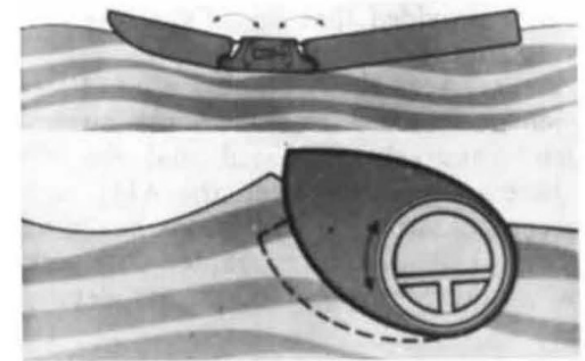

The Cockerell raft (top) and Salter duck

WAVE energy is not the white knight rescuing the fair society. That seems certain. Nevertheless the participants at a conference on the UK wave energy programme in London last week were optimistic about their ability to solve eventually the formidable problems of harnessing the power of the waves through steady work. And they were equally optimistic about the value of doing so.

The bad news about wave energy is that estimated costs per $\mathrm{kW}$ installed for the UK are $£ 5,000-£ 9,000$ compared to $£ 500-£ 1,000$ for a fossil or nuclear station. Current devices are a factor of 20 too costly for the value of the energy they can produce, concludes a report prepared by the consulting firm of Rendell, Palmer and Tritton in conjunction with Kennedy and Donkin. Referred to as a 'hatchet job' by observers outside the wave energy programme, the RPT report, commissioned by the Wave Energy Steering Committee, does not appear to have lowered morale. As Dr Stephen Salter of Edinburgh University, designer of one of the principal devices, the Salter duck put it: "Sir Hermann Bondi (Chief Scientist in the Department of Energy) has given us the best wings money can buy. RPT has told us how hard the ground is and the rest is up to us." Clive Crove Palmer, Programme Director of Harwell's Wave Energy Group told the conference: "This group thrives on problems and challenge. They won't just lick them, they'll eat them."

The high cost of the early designs arises from the diffuse character of the waves themselves. To capture the energy, large areas of device have to face the on-coming waves. With either concrete or steel the designs have been expensive. "But remember", says Grove-Palmer, "the Wright brothers' first estimate of the cost of air travel was $\$ 30,000$ per mile and they went right ahead".

The UK is favoured with some of the best off-shore sites in the world for the exploitation of wave power. Energy in waves is governed by wind strength and length of water over which the wind blows. Prevailing Westerly winds blowing across as much as 1,000 miles of the North Atalantic create waves of average power of $50 \mathrm{~kW}$ per metre of wave front.

Since the UK wave power programme is only two years old and since the conference participants have an obvious enthusiasm for what has been accomplished with the first generation devices, Grove-Palmer's optimism may be justified. What, then, has been achieved in two years?

Two of the main devices are the Cockerell raft and the Salter duck. The Cockerell raft uses the relative angular motion of two segments of raft and the Salter duck uses a similar action of oscillating pods about a common spine. The precise mode of conversion is a subject of study. The rocking action can be used to drive a pump which can pressurise a fluid which can drive a turbine. But other proposals include on site conversion to hydrogen, on site desalination or direct use of the mechanical power to make heat.

Other devices under active consideration are the oscillating water column (OWC) and the Lancaster University flexible bag. The OWC is a box with a hole in the top. The waves make the water level oscillate and air is forced through the hole to drive a turbine. The flexible bag is potentially the cheapest design. Air filled bags are attached to a submerged hull. The wave crests collapse the bags and the displaced air drives a turbine. The bags are filled during wave troughs from a low pressure duct.

Grove-Palmer detailed six areas of future work in his closing summary. - The need for better wave data. The irregularity of the waves in height and direction needs study. According to M. J. Platts of Wavepower Ltd, the builders of the Cockerell raft, one difficulty is that the oil industry has kept its accumulated wave data from the North Sea platforms 'inaccessible'. Platts has been unable even to arrange a visit to one of the platforms.

- Detailed critical engineering studies of how best to extract the power.

- Spine articulation of Salter's ducks. The bending moments are severe.

- Tests of the oscillating water column in real sea conditions.

- Further tests of the flexible bag because of its low cost.

- Mooring. Existing mooring equipment has been designed for ships and is unsuitable. Eauipment is needed to withstand powerful mooring forces in high seas, corrosion and fouling by marine organisms over a period of 25 years without inspection. (Ships get drydocked every three or four years).

- Size and survival in high seas.

Aside from the technical problems are the problems of actually producing a large scale operational system. M. J. Platts estimates that all the design problems need to be solved and a fully operational production system needs to be built before 1990 if there is to be significant $(20 \%)$ wave power production by 2020 . After 25 years, production must be entirely given over to replacement so building up sufficient capacity before that time is a problem. Platts also points out that on this time scale one can expect significant social and economic changes which are impossible to predict.

A novel feature of the wave energy programme is the attention now being paid to environmental and social aspects. Preliminary estimates indicate that the effect of wave energy devices $10 \mathrm{~km}$ off shore will be to increase the size of beaches and the economic well being of the local population. But the lobster, herring and the $£ 20,000,000$ salmon industry are concerned that ins'allation of the devices could interfere with the normal migration and mating behaviour of the fish. A third nuisance could be the possibility of seals finding the devices habitable with unknown consequences.

Problems of interfering with shioping are more serious. There are problems of collisions, the generation of rougher seas by wave reflections from the devices, and the need for reliable warning lights and radar reflectors to mark gaps up to $2 \mathrm{~km}$ wide to a standard much higher than ever attemp ${ }^{+}$ed in the open sea.

To many wave energy is an attractive alternative energy possibility. "There is still a major amount of work ahead before conclusions can be reached about the future of the technology" said Dr F. J. P. Clarke, Chairman of the Wave Energy Steering Committee. But realism must tell us that any talk of a full scale or near full scale wave energy station out at sea by the early 1980s is premature. We still have to evolve concepts and engineering designs that would justify the major expenditure involved in such a step." Clarke tempers his judgement with a more positive note. "The resultant [wave energy] team ... comprises a substantial national asset, and given continuous government support it is determined to find solutions. The natural resource is there and if anyone can learn how to capture it this team will."

Joe Schwartz 